\title{
QUANTITATIVE EVALUATION OF THE CIRCULANT PARTIAL DIALLEL CROSS
}

\author{
R. A. BRAY \\ C.S.I.R.O., Division of Tropical Pastures, St Lucia, Queensland, Australia
}

Received 1.ix.70

\section{INTRODUGTION}

IN breeding programmes, it is often necessary to evaluate different aspects of breeding behaviour for a large number of parents, and various methods have been suggested for this purpose. The complete diallel cross, involving all possible crosses between a set of parents, may be impractical in such cases. The partial diallel cross, which samples some of the crosses involved in the complete diallel, has sometimes been used (Kearsey, 1965; Dudley, Busbice and Levings, 1969). Different methods of sampling the complete diallel are possible (Curnow, 1963). Kempthorne and Curnow (1961) have given the theory and procedure for the analysis of the circulant sampling system, a balanced design where each parent is involved in the same number of crosses, and these crosses are allocated according to a simple formula.

It is important for the breeder to know the minimum number of crosses necessary to provide efficiently the desired information, since in many cases crosses are extremely difficult to make. This paper compares partial diallels and the complete diallel, each with the same number of parents. It is obvious that the partial diallels will generally be inferior to the complete diallel, simply because of their size. However, the extent of this inferiority needs to be determined because of the economic and statistical advantages offered by the design (Kempthorne and Curnow, 1961). The problem of comparing partial and complete diallels, each with the same number of crosses, is a different matter, and not considered here.

Comparing different-sized partial diallels using the same basic data has been attempted by Murty, Arunachalam and Anand (1967) and Anand and Murty (1969). These authors considered one particular subset of data at any one partial diallel size for any one character.

In the partial diallel cross, the particular subset of crosses to be sampled is determined by the original numbering of the parents. Any other ordering of parents may have given a different subset, and in fact for $P$ parents there are $(P !) / 2$ possible sets of partial diallels for any particular partial size. This number may be derived from the fact that there are $P$ ! possible orderings of parents, but reflections in order produce equivalent sets of data. It is doubtful that any single sampling of such a large number of possibilities can result in acceptable generalisations.

Arunachalam (1967) has published a computer program for partial diallel analysis. This program contains errors (see Appendix) and conclusions based on results from it (apparently those of Murty et al., 1967) are probably incorrect.

This paper reports the results obtained and conclusions drawn from different-sized partial diallels using 20 subsets of data for each size partial diallel. Twelve parents are involved, and data examined for six characters. 
The main concern is with comparisons within the partial diallel design. Comparisons of the efficiency of the partial diallel to that of other designs are outside the scope of this paper, but have received attention from other authors (Kempthorne and Curnow, 1961; Levings and Dudley, 1963; Kearsey, 1965).

\section{Materials AND Methods}

The data analysed were obtained during the course of a programme for breeding lucerne (Medicago sativa) in Queensland (Bray, 1970). A complete diallel cross was made between 12 parent clones, previously selected for yield characters, seed production and creeping-rootedness. Progeny were established as spaced plants, eight plants per plot, at Lawes, S.E. Queensland, in December 1967. There were four replications. Analysis was on the basis of plot means, taking no account of any reciprocal differences.

Data are reported for six characters:

I. Summer yield, February 1969: obtained by rating individual plants on a scale of 1 (small) to 5 (large).

II. Winter yield, July 1968: obtained by rating individual plants on a scale of 1 (small) to 10 (large).

III. Spring yield, September 1968: obtained as for II.

IV. Growth habit (procumbence), September 1968: obtained by rating individual plants on a scale of 1 (prostrate) to 5 (erect).

V. Percentage creeping-rooted plants, February 1969.

VI. Average plant diameter, February 1969: measured on a scale from 1 (diameter less than $38 \mathrm{~cm}$.) to 5 (diameter greater than 1 metre), The rating systems for yield had previously been established as accurate by comparing ratings with actual weights.

It is possible, with 12 parents, to form circulant partial diallels using three, five, seven and nine crosses per parent, and these are designated N3, N5, N7 and N9 respectively throughout the paper. N1l designates the full diallel, and $\mathcal{N}$ as a general term refers to the number of crosses per parent. The number of parents and the number of replications are symbolised by $P$ and $R$ respectively.

Analysis of the partial diallels was by the method of Kempthorne and Curnow (1961). The full diallel analysis is merely an extension of this, and corresponds to Method 4 of Griffing (1956). Details of the analysis of variance are shown in table 1 . When the analysis (as in this paper) is based on the means of crosses over all replicates, the expectations may be written as:

$$
\begin{aligned}
& \left.E \text { (Error mean square) }=\sigma_{e}^{2} \text { (actually } \sigma_{e}^{2} / R\right) \\
& E(\text { SCA mean square })=\sigma_{e}^{2}+\sigma_{s}^{2} \\
& E(\text { GCA mean square })=\sigma_{e}^{2}+\sigma_{s}^{2}+[\mathcal{N}(P-2) /(P-1)] \sigma_{\nu}^{2} .
\end{aligned}
$$

In different parts of the paper, both fixed and random models are used to illustrate different methods of analysis.

As shown above, there are many possbile different partial diallels (i.e. subsets of data) to be obtained from any one set of parents. Consequently, 


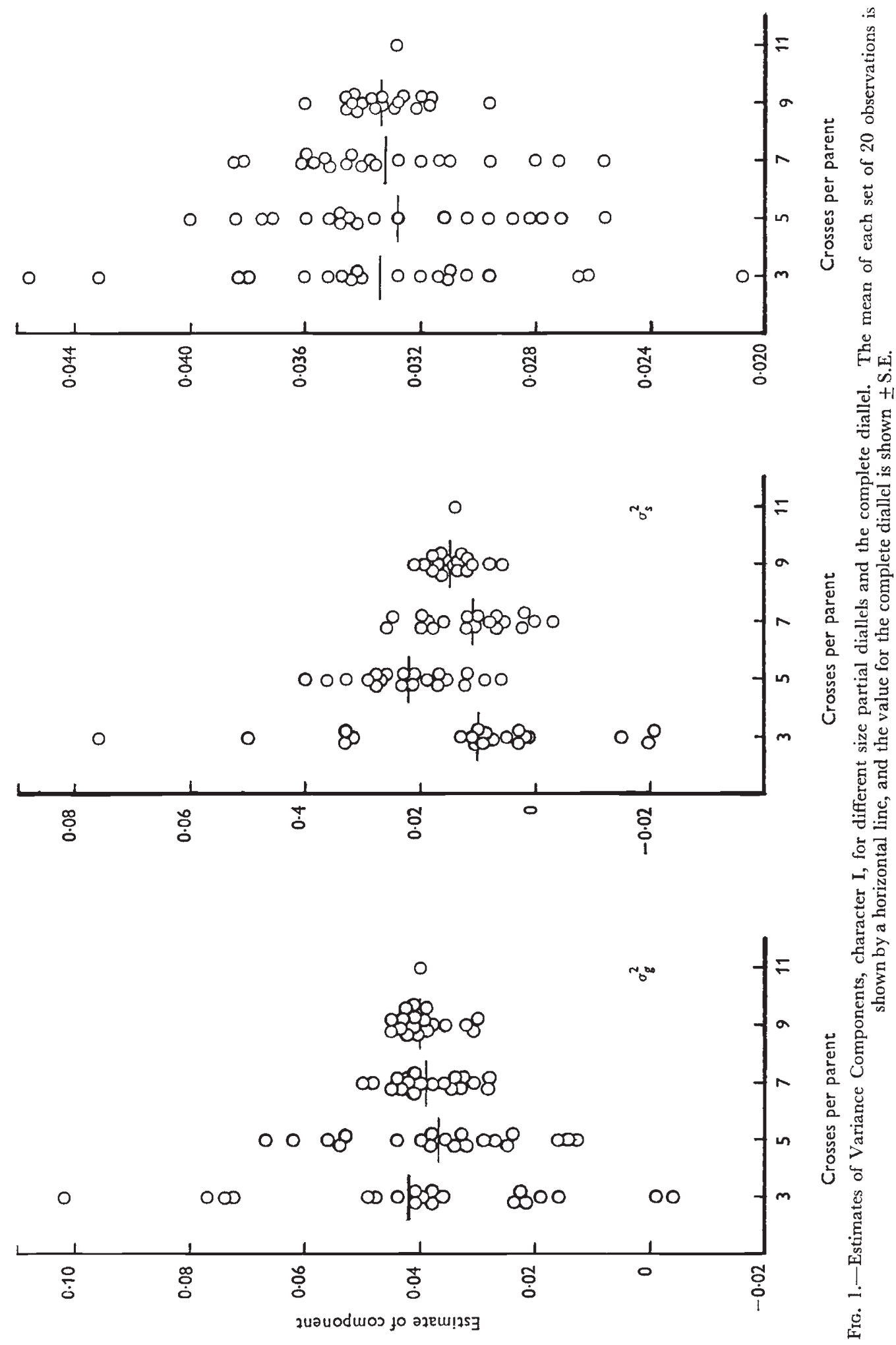


before each analysis the crosses to be sampled were determined by randomising the 12 parents and applying the usual formulae. Twenty different random orders of parents (subsets of data) were used for each sized partial diallel for each character. The nature and distribution of the various statistics obtained from these 20 samples provide information on the usefulness of various sized partial diallels.

The data were analysed as if for a diploid organism, since effects of polyploidy are not relevant to the present comparisons.

Throughout the paper the term "true value" is used to designate the estimates obtained from the full diallel, since this is the best estimate of the

\section{TABLE 1}

Analysis of variance of the partial diallel cross

\begin{tabular}{lll}
\multicolumn{1}{c}{ Source } & \multicolumn{1}{c}{ d.f. } & Expected values of mean squares \\
Replicates & $R-1$ & \\
General combining ability & $P-1$ & $\sigma_{e}^{2}+R \sigma_{s}^{2}+[R \mathcal{N}(P-2) /(P-1)] \sigma_{g}^{2}$ \\
Specific combining ability & $P(\mathcal{N} / 2-1)$ & $\sigma_{e}^{2}+R \sigma_{a}^{2}$ \\
Error & $(R-1)(P \mathcal{N} / 2-1)$ & $\sigma_{e}^{2}$ \\
Total & $R P \mathcal{N} / 2-1$ &
\end{tabular}

population constituted by the parents. The term does not infer anything concerning the population from which the parents were drawn. GCA and SCA are used for "general combining ability" and "specific combining ability" respectively.

\section{Results AND DisGUSSION}

The breeder may have any one of a number of reasons for performing the analysis: estimation of variance components, estimation of heritability, detection of GCA and SGA, comparing GGA effects, or selection of the best parents. Therefore several aspects of the analysis may be considered.

\section{(i) Estimation of variance components}

It can be seen from table 1 that the expected values of the variance components $\sigma_{g}^{2}$ (GCA variance), $\sigma_{s}^{2}$ (SCA variance) and $\sigma_{e}^{2}$ (error variance) are in no way dependent upon the size of the partial diallel (i.e. value of $\mathcal{N}$ ) except in precision of estimate. Thus, although estimates from a particular set of data may not approximate the true values (estimated from the full diallel) the means of several such estimates should be close to the true values. In fig. 1 , the estimates of $\sigma_{g}^{2}, \sigma_{s}^{2}$ and $\sigma_{e}^{2}$ for 20 different subsets of data for character I are plotted for the different sized partial diallels and the full diallel. It is apparent that single estimates of all three components may be grossly in error for small values of $\mathcal{N}$, but the means of the 20 estimates approximate the true values. The larger partial diallels (N7 and N9) show less variation, but individual estimates may still depart considerably from true values.

Data from the other five variables are not presented, but conformed to the same pattern. 


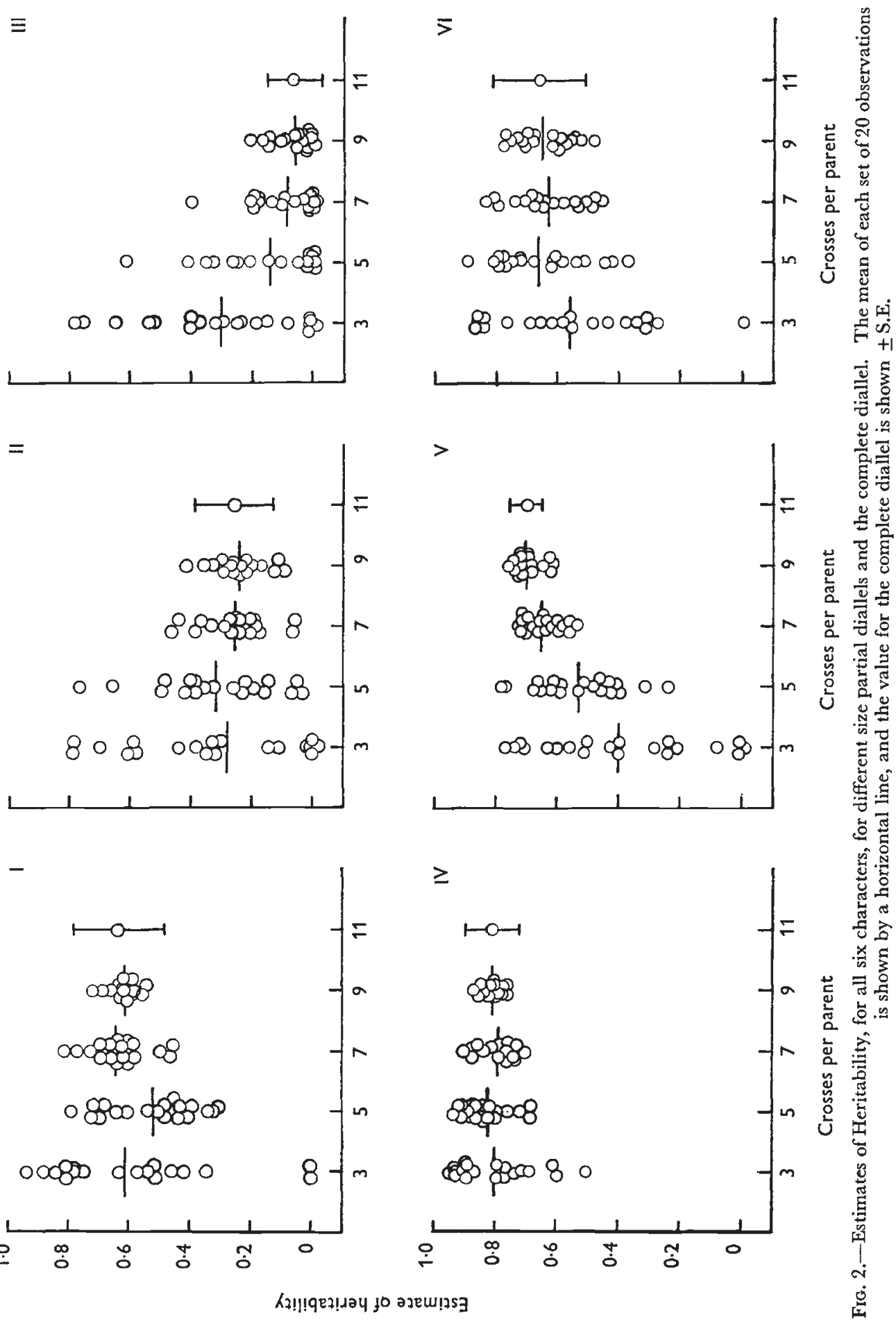




\section{(ii) Estimation of heritability}

Components of variation are generally used in combination to estimate heritability, which may then provide a guide for future breeding procedures.

Narrow sense heritability was estimated by

$$
h^{2}=\frac{4 \sigma_{g}^{2}}{4 \sigma_{g}^{2}+4 \sigma_{s}^{2}+\sigma_{e}^{2}} .
$$

This was calculated for all characters and all values of $\mathcal{N}$, and results plotted in fig. 2.

For four of the six characters, the mean heritability (from 20 subsets) is constant over different values of $\mathcal{N}$ (as expected), but individual estimates vary widely.

There are two reasons for the apparent trends in mean heritability values for characters III and V. Firstly, the particular samples of 20 used in N3 had (a) high GCA and low SCA estimates leading to high heritability estimates for character III, and (b) low GCA and high SCA estimates leading to low heritability estimates for character $\mathrm{V}$. In addition, since negative estimates of $\sigma_{g}^{2}$ were considered to indicate a heritability of zero rather than a negative value, means are therefore biassed upwards for character III.

The data illustrate the wide range of heritability estimates obtainable on the basis of a single subset. For all characters except IV, for N3, estimates of heritability range from 0 to over $0 \cdot 80$. For character III, for N3, ten out of 20 estimates were greater than 0.30 , compared with a true value of 0.09 . For character $\mathrm{V}$, for N3, eight out of 20 were less than 0.40 , with the true value being 0.68 . The chance sampling of one of these aberrant values could well lead to an erroneous conclusion concerning the parental material.

It is not practicable to point out all cases where there is agreement or non-agreement with the true values, but it is apparent that little confidence can be placed on estimates from small partial diallels. For all characters except V, N7 gives most heritability estimates within one standard error of the true value. (The standard error was calculated from the procedure given by Kempthorne (1957, p. 246) for calculating the variance of a ratio.) With a larger number of parents, the true heritability would be expected to have a smaller standard error, and it is not therefore possible to generalise concerning the number of crosses necessary to attain this precision of estimate.

\section{(iii) Detection of GCA and SCA}

For all six characters, the full diallel analysis indicated significant GCA. For characters II and III SCA was also significant $(P<0.01$ and $P<0.001$ respectively).

The significance levels of $F$ tests for the 20 subsets for each size partial diallel and each character are shown in table 2. While there is nothing absolute about any "level of significance", it is clear that in many cases the conclusions would be different to that obtained from N11, or at a different level of probability, for the smaller partial diallels.

Two types of error occur. Effects declared non-significant in NII may be declared significant (e.g. SCA, character IV) or effects declared significant 
in N11 may be declared non-significant (e.g. GCA, character V, N3). Both types of error could lead to disastrous mistakes in interpretation. In the six characters examined here, correct decisions concerning SCA would appear more difficult to reach than correct conclusions regarding GCA.

TABLE 2

Significance levels from $\mathrm{F}$ tests of general and specific combining ability. The number of cases falling into each class, for 20 sets of data for each size partial diallel, and the complete diallel

\begin{tabular}{|c|c|c|c|c|c|c|c|c|c|}
\hline \multirow[b]{2}{*}{ Character } & \multirow[b]{2}{*}{ Value of } & \multicolumn{4}{|c|}{ GCA (level of probability) } & \multicolumn{4}{|c|}{ SCA (level of probability) } \\
\hline & & $>0.05$ & 0.05 & 0.01 & 0.001 & $>0.05$ & 0.05 & 0.01 & 0.001 \\
\hline I & $\begin{array}{r}\mathcal{N} \\
3 \\
5 \\
7 \\
9 \\
11\end{array}$ & $\begin{array}{l}\bar{z} \\
\bar{z}\end{array}$ & $\begin{array}{l}\frac{3}{-} \\
- \\
-\end{array}$ & $\begin{array}{l}5 \\
- \\
-\end{array}$ & $\begin{array}{r}12 \\
20 \\
20 \\
20 \\
1\end{array}$ & $\begin{array}{r}18 \\
17 \\
19 \\
19 \\
1\end{array}$ & $\begin{array}{r}2 \\
2 \\
1 \\
1 \\
-\end{array}$ & $\begin{array}{l}\overline{1} \\
\overline{-}\end{array}$ & $\begin{array}{l}\overline{-} \\
\overline{-}\end{array}$ \\
\hline II & $\begin{array}{r}3 \\
5 \\
7 \\
9 \\
11\end{array}$ & $\begin{array}{l}5 \\
- \\
-\end{array}$ & $\begin{array}{r}4 \\
3 \\
3 \\
- \\
-\end{array}$ & $\begin{array}{r}6 \\
6 \\
1 \\
-\end{array}$ & $\begin{array}{r}5 \\
11 \\
17 \\
19 \\
1\end{array}$ & $\begin{array}{r}10 \\
13 \\
2 \\
- \\
-\end{array}$ & $\begin{array}{r}7 \\
2 \\
10 \\
4 \\
-\end{array}$ & $\begin{array}{r}3 \\
4 \\
6 \\
16 \\
1\end{array}$ & $\begin{array}{l}-1 \\
2 \\
-\end{array}$ \\
\hline III & $\begin{array}{r}3 \\
5 \\
7 \\
9 \\
11\end{array}$ & $\begin{array}{r}2 \\
3 \\
2 \\
-\end{array}$ & $\begin{array}{r}7 \\
4 \\
2 \\
1 \\
-\end{array}$ & $\begin{array}{r}10 \\
6 \\
6 \\
6 \\
-\end{array}$ & $\begin{array}{r}1 \\
7 \\
10 \\
13 \\
1\end{array}$ & $\begin{array}{r}17 \\
5 \\
- \\
-\end{array}$ & $\begin{array}{r}1 \\
4 \\
3 \\
1 \\
-\end{array}$ & $\begin{array}{r}2 \\
6 \\
9 \\
2 \\
-\end{array}$ & $\begin{array}{r}- \\
5 \\
8 \\
17 \\
1\end{array}$ \\
\hline IV & $\begin{array}{r}3 \\
5 \\
7 \\
9 \\
11\end{array}$ & $\begin{array}{l}E \\
z \\
-\end{array}$ & $\begin{array}{l}\bar{z} \\
\bar{z}\end{array}$ & $\begin{array}{l}\bar{z} \\
\bar{z}\end{array}$ & $\begin{array}{r}20 \\
20 \\
20 \\
20 \\
1\end{array}$ & $\begin{array}{r}18 \\
16 \\
13 \\
15 \\
1\end{array}$ & $\begin{array}{r}2 \\
4 \\
5 \\
4 \\
-\end{array}$ & $\begin{array}{l}- \\
2 \\
1 \\
-\end{array}$ & $\begin{array}{l}- \\
-\end{array}$ \\
\hline V & $\begin{array}{r}3 \\
5 \\
7 \\
9 \\
11\end{array}$ & $\begin{array}{r}4 \\
1 \\
- \\
-\end{array}$ & $\begin{array}{l}7 \\
- \\
-\end{array}$ & $\begin{array}{r}5 \\
5 \\
- \\
-\end{array}$ & $\begin{array}{r}4 \\
14 \\
20 \\
20 \\
1\end{array}$ & $\begin{array}{r}18 \\
19 \\
19 \\
20 \\
1\end{array}$ & $\begin{array}{r}2 \\
1 \\
1 \\
-\end{array}$ & $\begin{array}{l}\bar{Z} \\
\bar{Z}\end{array}$ & $\begin{array}{l}\overline{-} \\
\overline{-}\end{array}$ \\
\hline VI & $\begin{array}{r}3 \\
5 \\
7 \\
9 \\
11\end{array}$ & $\begin{array}{l}2 \\
- \\
-\end{array}$ & $\frac{1}{-}$ & $\frac{3}{-}$ & $\begin{array}{r}14 \\
20 \\
20 \\
20 \\
1\end{array}$ & $\begin{array}{r}17 \\
17 \\
13 \\
11 \\
1\end{array}$ & $\begin{array}{r}3 \\
2 \\
6 \\
9 \\
\end{array}$ & $\begin{array}{l}-1 \\
1 \\
-\end{array}$ & $\begin{array}{l}\overline{-} \\
\overline{-}\end{array}$ \\
\hline
\end{tabular}

If the conclusions from the $F$ tests for GCA and SGA are considered in conjunction (table 3 ) there are many instances where the overall conclusion regarding presence or absence of GCA and/or SCA would be different to that from N11. This is particularly so for characters II and III, where N11 showed significant SCA. For N9, characters III and VI, only 11 of the 20 samples gave the same conclusion as N11.

In general, the larger size partial diallels produce results which more closely approximate those from the full diallel. In the case of GCA, this is due to an increase in the number of cases declared significant (no character 
with non-significant GGA was included in this study). The reason for this is readily apparent from the expected values of mean squares (table 1 ). ${ }^{*}$ The Expected Value (GCA mean square) contains the factor $\mathcal{N}$, the number of crosses involved for each parent, and as $\mathcal{N}$ increases, so the expectation increases. This is illustrated in fig. 3 for character $\mathrm{V}$.

In contrast, the expectation of SCA mean square is constant for all $\mathcal{N}$. Thus the mean of SCA mean squares of the 20 subsets for each value of $\mathcal{N}$ should approximate the actual mean square for SCA obtained in N11. This is also shown in fig. 3. The values of SCA mean square vary widely for N3, N5 and N7, but become more precise with increase in $\mathcal{N}$. However, GCA mean square values remain variable up to N9 (for all characters) due to the increasing values of the mean squares.

TABLE 3

Significance levels from $F$ tests of general and specific combining ability. The number of cases of complete agreement between 20 sets of data for each partial diallel and the complete diallel

\begin{tabular}{crrrrrr} 
Value of $\mathcal{N}$ & \multicolumn{7}{c}{ Character } \\
3 & I & II & III & IV & V & VI \\
5 & 11 & 0 & 0 & 18 & 3 & 12 \\
7 & 17 & 2 & 2 & 16 & 13 & 17 \\
9 & 19 & 4 & 3 & 13 & 19 & 13 \\
19 & 15 & 11 & 15 & 20 & 11
\end{tabular}

Anand and Murty (1969) deduced that SGA is overestimated for small values of $\mathcal{N}$. On the average, this is not so, and reflects only the nature of the particular sample they analysed.

The calculated error mean squares are also shown in fig. 3. Once again, estimates become more precise as $\mathcal{N}$ increases. The one very low error term for N7 was the cause of the one significant $(P<0.05)$ SGA estimate for character $\mathrm{V}$ in table 2.

It is apparent from the above considerations that any one individual subset of data for N3 and N5 (and for some characters N7 and N9) would only rarely lead to correct interpretation of data with respect to the full population of inference (i.e. all parents).

One of the advantages of the partial diallel over the full diallel is the relatively greater degree of precision attained in tests for GGA mean square, since available degrees of freedom are more evenly partitioned (Kempthorne and Curnow, 1961). However, this increase in precision appears to be largely vitiated by the decrease in expected value of the GCA mean square.

\section{(iv) Estimates of general combining abilities of parents}

(a) Actual estimates

The general combining ability effect of each parent $\left(\hat{g}_{i}\right)$ may be estimated. Murty et al. (1967) concluded from their data that small partial diallels overestimate the individual $\hat{g}_{i}$. However by definition,

$$
\Sigma \hat{g}_{i}=0
$$

* The expected value for GCA mean square under a fixed effects model is

$$
\sigma_{e}^{2}+\frac{\mathcal{N}(P-2)}{(P-1)^{2}} \Sigma \hat{g}_{i}^{2}
$$




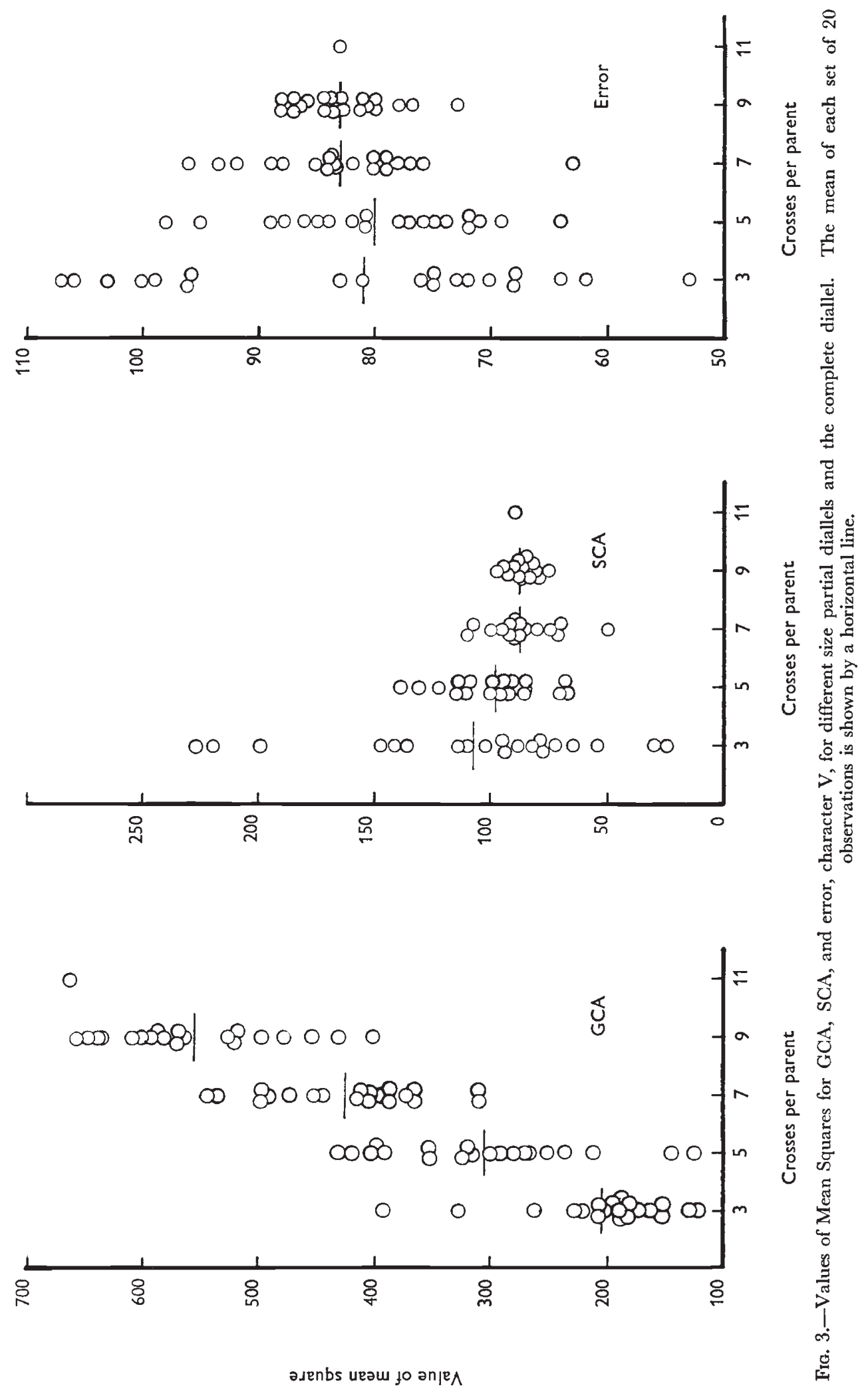


so this cannot be true. Over a number of subsets of data

$$
E\left(\hat{g}_{i}\right)=g_{i} \text {, for all } i \text {. }
$$

Figure 4 shows the means of 20 values of some $\hat{g}_{i}$, for characters III and VI for different values of $\mathcal{N}$. For clarity, not all $12 \hat{g}_{i}$ are shown. Those
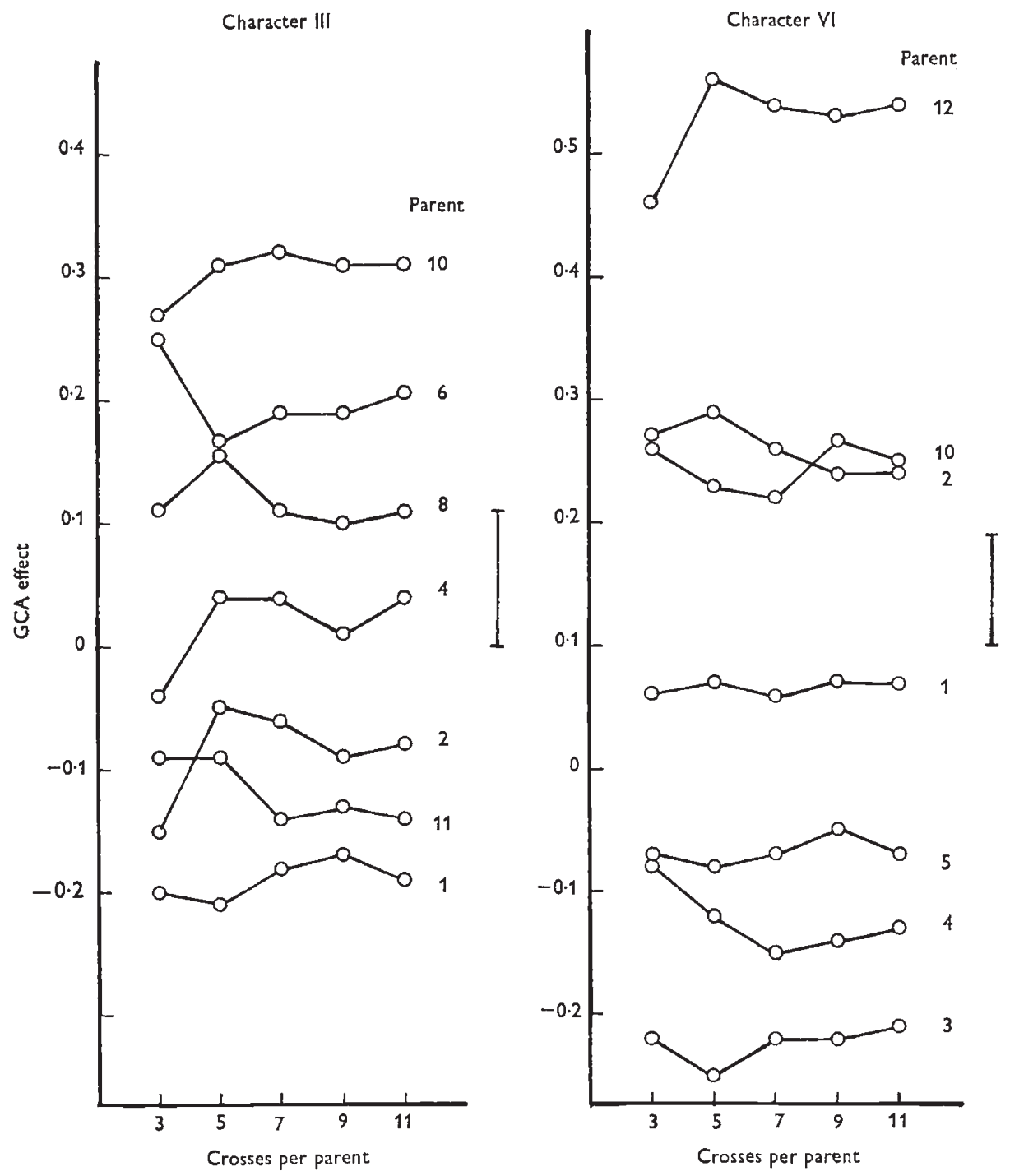

Fig. 4.-Estimates of general combining ability effects, characters III and VI, for different size partial diallels and the complete diallel. Values for partial diallels are means of 20 observations. The vertical line shown is the S.E. of the difference between any two GCA effects for the complete diallel.

not represented had similar trends. The general trend is for the mean of any $\hat{g}_{i}$ to be consistent for different values of $\mathcal{N}$. The variation between means of estimates of any one $\hat{g}_{i}$ is small compared to the standard error of 
the difference between N11 estimates of any two $\hat{g}_{i}$. (This S.E. is of course not valid for means of estimates.)

Although the mean values are reliable estimates of the true value, individual estimates of any $\hat{g}_{i}$ can vary tremendously for different subsets of data. Maximum and minimum values of $\hat{g}_{i}$ from 20 subsets of data for character III are given in table 4. Little faith can be placed in estimates from small size partials as predictors of population values.

TABLE 4

Maximum and minimum estimates of general combining ability effects, character III, for some of the 12 parents, over different size partial diallels

$\begin{array}{rrrrrrrrrrr}\text { Parent } & \overbrace{\text { Min. Max. }}^{3} & \overbrace{\text { Min. Max. }}^{5} & \overbrace{\text { Min. }}^{2} \\ 1 & -0.74 & 0.38 & -0.50 & 0.01 & -0.37 & 0.00 & -0.22 & -0.11 & -0.19 \\ 2 & -0.87 & 0.23 & -0.39 & 0.29 & -0.26 & 0.18 & -0.19 & 0.00 & -0.08 \\ 4 & -0.65 & 0.52 & -0.39 & 0.30 & -0.14 & 0.17 & -0.06 & 0.15 & 0.04 \\ 6 & -0.35 & 0.66 & -0.16 & 0.52 & -0.07 & 0.32 & 0.12 & 0.29 & 0.21 \\ 10 & -0.37 & 0.88 & -0.04 & 0.66 & 0.18 & 0.45 & 0.23 & 0.39 & 0.31\end{array}$

\section{(b) Detection of differences}

The formula for the average variance of the difference between two $\hat{g}_{i}$ is given by Kempthorne and Curnow (1961) as:

$$
\text { Av. } V\left(\hat{g}_{i}-\hat{g}_{j}\right)=2\left(\frac{P a^{0}}{P-1}-\frac{1}{2 \mathcal{N}(\bar{P}-1)}\right)\left[\sigma_{s}^{2}+\sigma_{e}^{2} / R\right] \text {, }
$$

where $P$ is the number of parents, $\mathcal{N}$ is the number of crosses per parent, and $a^{0}$ is the diagonal term in the inverse of the cross matrix.

For a constant number of replicates, for a particular set of data, this variance is proportional to

$$
\left(\frac{P a^{0}}{P-1}-\frac{1}{2 \mathcal{N}(P-1)}\right)=k
$$

since $E\left(\sigma_{s}^{2}+\sigma_{e}^{2} / R\right)$ is constant for all $\mathcal{N}$. The value of $k$ is approximately equal to $a^{0}$ for large values of $P$. If values of $k$ are plotted for different values of $\mathcal{N}$ (fig. 5) it is clear that the greatest reduction in the magnitude of $k$ (and hence the variance of the difference) takes place at small values of $\mathcal{N}$. It would not seem worth while, even for large numbers of parents, to make $\mathcal{N}$ greater than 8 or 10 . The numbers of parents and crosses used by Dudley et al. (1969) $(P=75, \mathcal{N}=4)$ would lead to quite high estimates of this variance, which would have been reduced by a factor of approximately 3 by increasing $\mathcal{N}$ to 6 , although this would of course mean increasing the size of the experiment by 50 per cent.

The suggestion by Murty et al. (1967) and Anand and Murty (1969) that a value of $\mathcal{N}$ equal to $P / 2$ may be necessary to adequately assess large numbers of parents would not seem to be supported by this aspect of analysis since any increase in $\mathcal{N}$ above 10 leads to relatively little decrease in the appropriate variance, for any number of parents. 


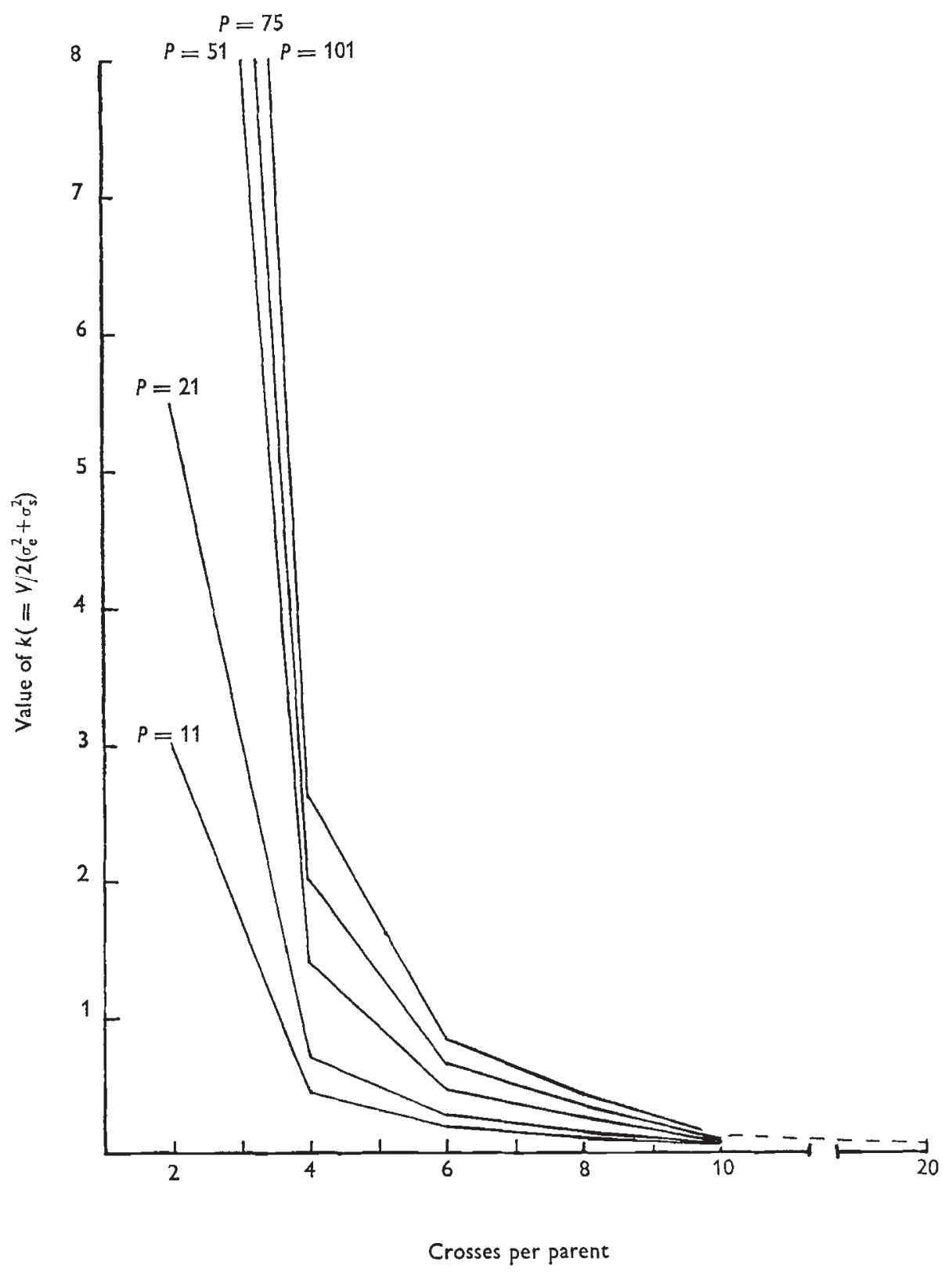

FIG. 5.-The effect of different numbers of crosses on the variance of the difference between general combining ability effects, for different numbers of parents. 
For the data considered in this paper, within any set of 20 samples, for any value of $\mathcal{N}$,

Average Variance $\left(\hat{g}_{i}-\hat{g}_{j}\right) \propto\left(\hat{\sigma}_{s}^{2}+\hat{\sigma}_{e}^{2}\right)$.

For character IV, N3, these variances ranged from 0.0257 to 0.1400 , for N5 from 0.0145 to 0.0324 , for N7 from 0.0086 to 0.0190 , and for N9 from 0.0074 to 0.0108 .

\section{(v) Selection of individual parents}

If a character is shown to have high heritability it may be desirable to select a certain proportion of parents for further crossing. As an example, consider character IV, where all heritability estimates exceeded $0 \cdot 50$, and assume it is desired to select the best 25 per cent. of parents (in this case, three). For N3, this would have resulted in 15 different sets of three parents being selected in 20 samples, with nine of the 12 parents represented at least once. For N5, there were five sets (one occurring 11 times), representing six parents. For N7, there were three sets (one 15 times), representing five parents, and N9 gave 20 identical sets. For characters with lower heritability the lack of efficiency of small-size partials in determining " best" parents is even more marked. With a large number of parents, small values of $\mathcal{N}$ could frequently lead to errors in selection.

\section{Conclusions}

It is quite clear that the use of a partial diallel of any size entails a considerable risk, in that only part of the potentially available data is being sampled. Statistical estimates or conclusions may be far removed from the actual values for the population of parents. The extent of any such error, and the likelihood of it, depend upon both the number of crosses sampled and the nature of the character under study. Characters for which parents exhibit specific combining ability would seem to be particularly prone to misinterpretation.

It is not possible to state categorically an optimum size for the partial diallel, although more than eight or ten crosses per parent would probably be unnecessary. Within any one population, different numbers of crosses might suffice for different characters. The actual numbers of crosses made must of course take into account economic factors as well as statistical reasoning.

\section{Summary}

1. Data for six characters from a 12-clone diallel of lucerne (Medicago sativa) are analysed as full and partial diallel sets.

2. Twenty different subsamples of data are taken for each size partial diallel, as opposed to only one in previous work reviewed.

3. Small partial diallels provide poor estimates of heritability for most characters.

4. Detection of general and specific combining ability is uncertain in small partial diallels, and varies between characters. 
5. For detection of differences between general combining abilities, there seems to be little advantage in having more than 8 to 10 crosses per parent, compared to the previously published suggestion of half the number of parents.

6. Selection of desirable parents is imprecise in small diallels.

7. It is not considered possible to state a generalised optimum value for the number of crosses per parent, since this varies with the character to be studied, and also needs economic consideration.

Acknowledgments. - This work was supported by a grant from the Australian Meat Research Committee.

\section{REFERENCES}

ANAND, I. J., AND MURTY, B. R. 1969. Serial analysis of combining ability in diallel and fractional diallel crosses in linseed. Theor. Appl. Genet., 39, 88-94.

ARUnAchalam, v. 1967. Computer programmes for some problems in biometrical genetics. IV. Analysis of combining ability by partial diallel crosses. Ind. Jour. Genet. Pl. Breed., 27, 392-400.

BRAY, R. A. 1970. Development of grazing lucerne for subtropical conditions. Proc. 11th Int. Grassld Cong., Surfers Paradise, Queensland, Aust., 261-263.

Curnow, R. N. 1963. Sampling the diallel cross. Biometrics, 19, 287-306.

DUDLEY, JOHN W., BUSBICE, T. H., AND LEVINGS, C. S. III. 1969. Estimates of genetic variance in "Cherokee" alfalfa (Medicago sativa L.). Crop Sci., 9, 228-231.

GRIFFING, B. 1956. Concept of general and specific combining ability in relation to diallel crossing systems. Aust. Four. Biol. Sci., 9, 463-493.

KEARSEY, M. J. 1965. Biometrical analysis of a random mating population: a comparison of five experimental designs. Heredity, 20, 205-235.

Kempthorne, o. 1957. An Introduction to Genetic Statistics. Wiley, N.Y.

KEMPTHORNE, O., AND CURNOW, R. N. 1961. The partial diallel cross. Biometrics, 17, 229-250. LEVINGS, C. S. III, AND DUDLEY, J. W. 1963. Evaluation of certain mating designs for estimation of genetic variance in autotetraploid alfalfa. Crop Sci., 3, 532-535.

MURTY, B. R., ARUNAChAlAM, v., AND ANAND, I. J. 1967. Diallel and partial diallel analysis of some yield factors in Linum usitatissimum. Heredity, 22, 35-41. 


\section{APPENDIX}

$A$ correction to a published analysis of the partial diallel cross

In addition to minor textual errors, the program of Arunachalam (1967) contains two errors in statistical procedure.

1. The Error sums of squares (SS) has been obtained by:

instead of

$$
\text { Total SS - Replications SS-GCA SS }
$$

$$
\text { Total SS - Replications SS - Cross SS }
$$

where Cross SS is based on totals of crosses over replications.

2. Specific combining ability sums of squares has been obtained by:

$$
\text { SCA SS = Cross SS - GCA SS. }
$$

However, the GCA sums of squares calculated by the method of Kempthorne and Curnow (1961) is based on means of crosses over replications.

Therefore

$$
\text { SCA SS = (Cross SS/Number of replications) - GCA SS. }
$$

The two analyses are compared in Appendix table 1 for the data used

$$
\text { APPENDIX-TABLE } 1
$$

Analysis of variance of the partial diallel cross, by two different methods

\begin{tabular}{llrrrc} 
& \multicolumn{1}{c}{ Source } & d.f. & \multicolumn{1}{c}{ S.S. } & M.S. & F \\
1. According to & Replications & 2 & 81.51 & - & - \\
Arunachalam & GCA & 9 & 685.51 & 76.17 & 0.92 \\
& SCA & 5 & 1525.17 & 305.03 & 3.69 \\
& Error & 28 & 2317.53 & 82.77 & - \\
& Total & 44 & 3084.55 & - & - \\
2. Correct & & & & & \\
& Replications & 2 & 81.51 & - & - \\
& Crosses & 14 & $2210 \cdot 66$ & - & - \\
& Error & 28 & 792.36 & 28.30 & - \\
& Total & 44 & 3084.53 & - & -
\end{tabular}

which leads to

$\begin{array}{lrrrrl}\text { GCA } & 9 & 685.51 & 76.17 & 8.08 \quad \mathrm{P}<0.001 \\ \text { SCA } & 5 & 51.37 & 10.28 & 1.09 \quad \mathrm{P}>0.05 \\ \text { Error } & 28 & - & 9.43 & -\end{array}$

in Arunachalam's example. The conclusion from the published example of non-significant GCA, and significant $(P<0.05)$ SCA is wrong. The correct conclusion is that the $F$ test for GCA is highly significant $(\mathrm{P}<0.001)$ and SCA is non-significant. One effect of Arunachalam's program is to overestimate SCA, and relatively to underestimate GCA.

The correctness of the present method is easily verified. The expected mean value of each cross, in the absence of SCA is:

$$
X_{t j}=\hat{\mu}+\hat{g}_{i}+\hat{g}_{j}
$$

where $\hat{g}_{i}$ is the estimated general combining ability effect. If the differences 
between observed (from Arunachalam's data) and expected values are calculated, the sums of squares of these differences is $51 \cdot 37$, identical with the calculated SCA sums of squares.

\section{REFERENCES}

ARUNACHalam, v. 1967. Computer programmes for some problems in biometrical genetics.

IV. Analysis of combining ability by partial diallel crosses. Ind. Four. Genet. Pl. Breed., $27,392-400$.

KEMPTHORNE, O., AND CURNOW, R. N. 1961. The partial diallel cross. Biometrics, 17, 229-250. 